\begin{tabular}{|c|c|c|}
\hline 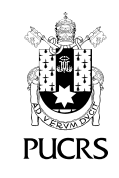 & $\begin{array}{l}\text { ESCOLA DE } \\
\text { HUMANIDADES }\end{array}$ & $\begin{array}{l}\text { Revista Digital do Programa de Pós-Graduação em Letras da PUCRS } \\
\text { Letrônica, Porto Alegre, v. 14, n. 2, p. 1-17, abr.-jun. } 2021 \\
\text { e-ISSN: } 1984-4301\end{array}$ \\
\hline http://dx & $\mathrm{rg} / 10.15448 / 1984-4301.2021 .2 .38745$ & \\
\hline
\end{tabular}

SEÇÃO: ARTIGOS

\title{
Estudo piloto de validação do conteúdo e da confiabilidade de uma tarefa de uso da estratégia de predição leitora aplicada a estudantes do ensino fundamental
}

\author{
Pilot study of content and reliability validation of a reading prediction strategy task \\ usage applied to elementary school students
}

\section{Danielle Baretta ${ }^{1}$ orcid.org/0000-0003-2679-7671 daniellebaretta@hotmail.com}

\section{Caroline Bernardes \\ Borges $^{1}$ \\ orcid.org/0000-0001-8815-9195 caroline.borges93@edu.pucrs.br}

\section{Patricia de Andrade Neves $^{1}$}

orcid.org/0000-0002-1981-5002 andradeneves.patricia@gmail.com

Recebido em: 30 jul. 2020. Aprovado em: 8 jan. 2021. Publicado em: 10 agos. 2021.
Resumo: Considerando a importância das estratégias de leitura para o processo de compreensão leitora, elaborou-se um instrumento para examinar o uso da predição leitora por alunos do ensino fundamental. O objetivo desse estudo é apresentar o processo realizado para a validação do conteúdo e da confiabilidade dessa tarefa de uso da predição leitora aplicada a alunos do $6^{\circ}$ ano do ensino fundamental. Para a validação de conteúdo, realizou-se um painel de juizes que avaliaram o instrumento quanto à pertinência conceitual, à clareza, à adequação da linguagem, e à forma de apresentação. A validade de conteúdo foi verificada também por meio da análise das respostas dos estudantes. Para examinar a confiabilidade do instrumento, verificou-se a consistência interna dos itens. Os resultados indicaram que houve validade de conteúdo pela análise dos juizes e das respostas dos alunos. Constatou-se também a confiabilidade da tarefa por meio do coeficiente alfa de Cronbach. A partir dessa validação, considerou-se possivel a aplicação do instrumento a uma amostra maior e mais representativa. Palavras-chave: Predição leitora. Consciência textual. Ensino fundamental. Validade do teste.

Abstract: Considering the importance of reading strategies for the reading comprehension process, an instrument was developed to examine the use of reading prediction by elementary school students. The purpose of this study is to present the process performed to validate the content and reliability of this reading prediction task usage applied to 6th grade elementary school students. For content validation, there was a panel of judges that evaluated the instrument for conceptual relevance, clarity, language adequacy, and presentation. Content validity was also verified through the analysis of the students' answers. For the reliability analysis, the internal consistency of the items was verified. The results indicated that there was content validity through the analysis of the judges and the students' answers. The reliability of the task was also established using Cronbach's alpha coefficient. Through this validation, it was considered possible to apply the instrument to a larger and more representative sample.

Keywords: Reading prediction. Textual awareness. Elementary school. Test validity.

\section{Introdução}

Nas últimas décadas, tem crescido o número de pesquisas que estudam a forma como os alunos processam a leitura, buscando compreender os caminhos cognitivos percorridos pelo leitor na construção do sentido do texto. Esses estudos têm destacado a importância das estratégias de leitura, uma vez que é por meio delas que o leitor interage com o texto na busca da compreensão. Dentre os diferentes tipos 
nomeados pela literatura, a predição leitora, isto é, a antecipação de conteúdos do texto, tem se destacado como componente importante no processamento cognitivo da leitura (GOODMAN, 1976; GIASSON, 2000; PEREIRA, 2002; 2009; 2011; 2012; SMITH, 2003; CASTRO; PEREIRA, 2004; SPINILLO; ALMEIDA, 2014; SPINILLO; MAHON, 2015: PEREIRA; SANTOS, 2017). Além do reconhecimento da relevância das estratégias de leitura, pesquisas recentes (SPINILLO; MOTA; CORREA, 2010; LORANDI et al., 2012; ANÇÃ, 2015; PEREIRA; SANTOS, 2017) sugerem que a eficácia do processo de leitura está relacionada à habilidade do individuo de refletir sobre os próprios conhecimentos linguísticos, isto é, à sua consciência linguistica.

Tendo em vista estes aspectos, elaborou-se instrumento para examinar o uso da predição leitora e a consciência no uso dessa estratégia por alunos do ensino fundamental. Uma etapa importante desse processo é a validação do instrumento, que visa verificar a adequação e confiabilidade do teste aos objetivos estabelecidos. Esse é um processo contínuo que aprimora o instrumento através de ajustes precisos (RAYMUNDO, 2009). A validação, juntamente com a aplicação adequada do instrumento, permite que interpretações adequadas e corretas dos dados e, por sua vez, dos resultados sejam realizadas (MACÍAS, 2007).

Dessa forma, o presente estudo² tem por objetivo apresentar a validação de conteúdo e de confiabilidade de um instrumento de pesquisa cujo enfoque foi a investigação do uso da estratégia de predição leitora e da consciência no uso dessa estratégia por alunos do $6^{\circ}$ ano do ensino fundamental.

Para tanto, são apresentados, a seguir, os fundamentos teóricos do estudo, a metodologia utilizada e os resultados obtidos e, por fim, as conclusões.

\section{Fundamentação teórica}

Apresentam-se, nesta seção, os fundamentos teóricos que embasam o estudo relatado neste artigo. Para tanto, primeiramente são apresentados os pressupostos acerca do processo de validação de instrumentos de pesquisa e suas implicações, e, na segunda subseção, são apresentados os fundamentos psicolinguísticos que embasaram a elaboração do instrumento de pesquisa.

\subsection{Processo de validação de instrumentos de pesquisa}

As contribuições teóricas e metodológicas possibilitadas pelas pesquisas que investigam tópicos diversos a partir da elaboração e da aplicação de instrumentos são cada vez mais necessárias. No entanto, é importante que os testes elaborados sejam validados empiricamente, de modo que as conclusões às quais se chega a partir de seus resultados não sejam limitadas ou até mesmo equivocadas. É possível que ocorra má interpretação dos fenômenos quando os testes são elaborados e/ou aplicados de forma inadequada e sem critérios bem definidos e consistentes (SHOHAMY, 1994).

Desse modo, no que tange às pesquisas sobre o ensino, Urbina (2007) diz que, para a identificação de dificuldades quanto ao processo de ensino e aprendizagem, é necessário que informações válidas e fidedignas sejam fornecidas pelos instrumentos. Somente dessa forma as contribuições serão eficazes em relação ao que e como se ensina, gerando implicações pedagógicas coerentes.

Para que julgamentos e interpretações subjetivos sejam evitados - ou, pelo menos, minimizados - e para que o instrumento realmente seja eficaz para mensurar aquilo para o qual foi elaborado no que se refere à verificação e à avaliação, é indispensável que possua validade (VIANNA, 1978). De acordo com Vianna (1978), o processo de validação inicia e termina por meio de julgamento humano e, por isso, requer que o pesquisador dispense tempo, esforço e pensamento criativo e criterioso para elaborar o instrumento.

Urbina (2007) aponta que a validade se refere à propriedade do instrumento relacionada ao grau de evidências que apresenta de modo a sustentar as interpretações obtidas por meio de sua apli-

\footnotetext{
2 O presente estudo constitui-se em uma das etapas do projeto intitulado Compreensão leitora e consciência textual: um estudo com alunos do $6^{\circ}$ ano do ensino fundamental a partir da leitura de uma fábula, desenvolvido na PUCRS, no período de 2015 a 2016.
} 
cação. Cunha e Santos (2014) declaram que, de acordo com as American Educational Research Association, American Psychological Association \& National Council on Measurement in Education (1999), existem diferentes fontes de validade, que podem ser divididas em cinco eixos: conteúdo do teste, processo de resposta do teste, estrutura interna do teste, relações com outras variáveis e consequências do teste.

Raymundo (2009, p. 87), por sua vez, define a validação como "processo de examinar a precisão de uma determinada predição ou inferência realizada a partir dos escores de um teste" . Validar envolve demonstrar o valor do instrumento de medida e do processo de investigação que estão sendo utilizados. O processo de validação deve ser continuo, sendo repetido quantas vezes forem necessárias, de modo a indicar ajustes necessários e precisos para o aprimoramento da investigação. Desse modo, não somente o teste é validado, mas também toda a interpretação dos dados obtidos por meio daquele procedimento específico.

Com isso, entende-se que a validade do teste inicia no momento de seu planejamento, sua elaboração e sua construção e continua durante a aplicação, a correção e a interpretação dos resultados, abrangendo todas essas etapas (RAYMUNDO, 2009). De acordo com a autora, existem três aspectos da validade que estão relacionados aos objetivos de um instrumento: conteúdo, critério e construto.

A validade de conteúdo está relacionada ao julgamento sobre o instrumento em si, considerando se ele engloba os diferentes aspectos do seu objeto e não contém elementos que podem ser atribuidos a outros objetos que não correspondam àqueles investigados. Assim, serve para examinar se os conceitos abstratos da(s) teoria(s) investigada(s), que originaram o teste, estão representados adequadamente, sendo indicadores observáveis e mensuráveis da qualidade dos itens.

Um dos métodos empíricos pelos quais ocorre a validação do conteúdo é o chamado painel de juízes, que se refere a um grupo formado por especialistas que julgam se os itens constituintes do teste são representativos e pertinentes em relação às áreas de conteúdo a serem medidas e aos objetivos da investigação. O resultado do julgamento do painel de juizes pode ser utilizado pelo pesquisador na definição dos itens que serão mantidos, revisados ou eliminados (EXNER, 1993).

O planejamento do teste influencia na validade de conteúdo, pois constitui o momento em que é organizada a amostra representativa de conhecimentos, de processos cognitivos e de comportamentos pertinentes para atender aos objetivos do estudo. Além disso, atenta-se para a importância do trabalho cooperativo para o cuidado em relação aos julgamentos subjetivos, que devem ser sempre evitados.

No que se refere ao contexto escolar, é importante salientar que a validade de conteúdo de um teste não é permanente, visto que o processo educacional sofre mudanças com o tempo - como ocorre em qualquer outro contexto -, principalmente no que se refere à estrutura curricular. Desse modo, Raymundo (2009) ressalta que um instrumento possui validade de conteúdo por um determinado momento, em um contexto específico, até mesmo em função da evolução científica.

Macias (2007) diz que o processo de validação viabiliza e garante que a medida utilizada indique o significado verdadeiro das pontuações obtidas. Portanto, a validação, combinada à aplicação adequada dos instrumentos, permite que sejam realizadas interpretações adequadas e corretas dos dados e, consequentemente, dos resultados, considerando o(s) construto(s)/variável(is) os quais o pesquisador pretende medir.

No tocante à construção de instrumentos de consciência linguística e, mais especificamente, de consciência textual, é necessário considerar, além dos aspectos já citados, as características específicas relacionadas a esse constructo. Segundo Gombert (1992), o enfoque na consciência textual envolve o direcionamento do leitor para a reflexão sobre os elementos textuais constitutivos da situação comunicativa - incluindo os aspectos de coesão, coerência e superestrutura, que serão abordados de forma mais detalhada na seção seguinte, destinada à explicitação dos fundamentos relacionados ao conteúdo do instrumento. 
Segundo Maluf e Gombert (2008), a consciência linguística envolve a capacidade que os individuos possuem de tratar a lingua como objeto de análise, refletindo sobre seus elementos, além de controlar e planejar seus processos relacionados à linguagem.

Para que a pesquisa sobre esses aspectos seja possivel, geralmente são utilizados protocolos verbais para verificar os niveis de consciência linguistica do individuo. Segundo Baretta (2017, p. 48-49), o protocolo verbal pode ser definido como uma ferramenta que

consiste em explicitar pensamentos por meio da verbalização, o que a torna uma estratégia eficaz para conhecer processos realizados pela mente humana, ainda que os dados obtidos possam ser restritos, pois dependem da capacidade e motivação do individuo para a realização das verbalizações, bem como de sua familiaridade com a técnica.

Percebe-se, assim, a atividade de reflexão do individuo sobre as estruturas e os processos linguisticos de maneira intencional, expressada verbalmente por meio da oralidade ou da escrita a partir de perguntas estrategicamente direcionadas para obter tais respostas. Segundo Cohen (1987), os protocolos verbais são classificados em três tipos - autorrelatório, auto-observação e autorrevelação -, dependendo dos dados que se pretende coletar e dos processos que necessitam ser realizados.

O autorrelatório, segundo Tomitch (2007), é utilizado em pesquisas que requerem descrição sobre a leitura em geral de modo geral, envolvendo, por exemplo, percepções subjetivas do leitor sobre sua leitura ou uma pesquisa sobre hábitos de leitura. Já o protocolo de auto-observação busca levar o indivíduo a descrever uma situação especifica de leitura, realizada em um momento anterior; Ericsson e Simon (1993) sugerem que seja realizado logo após o término da leitura, visto que um intervalo de tempo maior comprometeria a espontaneidade das respostas dadas pelos participantes. Por fim, o protocolo de autorrevelação é utilizado quando é necessário que o leitor descreva seu processo de leitura enquanto a realiza, ideal para situações de pesquisas sobre o processo e não sobre o produto da leitura (TOMITCH, 2007).
O processo de validação precisa considerar todos esses aspectos, sendo de suma importância para o avanço científico, pois resultados fidedignos somente são encontrados por meio da aplicação de instrumentos que estejam alinhados, considerando os aspectos teóricos e metodológicos que os envolvem.

Além disso, considerando que a validação realizada neste estudo envolve pesquisa relacionada ao ensino, salienta-se a importância desse processo para implicações pedagógicas coerentes. A partir de uma interpretação adequada dos resultados, por meio da aplicação de testes validados, as conclusões às quais o pesquisador chega são reais e, desse modo, podem indicar caminhos e soluções pedagógicas adequadas para as dificuldades de leitura presentes no ensino.

A seguir, apresentam-se os fundamentos acerca da elaboração do instrumento.

\subsection{Elaboração do instrumento: compreensão leitora, predição e consciência textual}

O estudo para o qual o instrumento aqui analisado (sob o viés de seu processo de validação) foi elaborado está ancorado em fundamentos psicolinguísticos sobre o processo da leitura. Desse modo, nesta seção são apresentados, primeiramente, alguns estudos já realizados nesse sentido e, em seguida, os pressupostos teóricos que embasaram a elaboração do instrumento, envolvendo considerações sobre o processamento cognitivo da leitura, sobre o uso das estratégias de leitura - em especial a predição, investigada no instrumento - e sobre a consciência linguística, focalizando a consciência textual.

Quanto aos estudos sobre o tópico - relacionados a instrumentos construídos e/ou já validados no que se refere à consciência linguistica e à consciência textual -, realizados no Brasil, destacam-se os citados a seguir. Albuquerque e Spinillo (1997) investigaram os critérios que as crianças adotavam para identificar a carta e a notícia de jornal; Ferreira e Spinillo (2003) deram sequência ao estudo anterior, investigando a possivel progressão desses critérios no que tange ao avanço da idade, da escolaridade e da 
classe social; Spinillo e Pratt (2005), por sua vez, pesquisaram o papel desempenhado por intervenções relacionadas à consciência metatextual e à produção de textos.

Cunha e Santos (2014), em estudo sobre a validação de questionário de avaliação da consciência metatextual, realizada a partir da análise de juizes, investigaram a estrutura do instrumento e a relação com outras variáveis, como anos escolares e construtos relacionados, além da consistência interna dos itens. Neves e Borges (2018) e Neves, Borges e Baretta (2020) apresentaram e analisaram instrumento de verificação da consciência textual direcionado a alunos do $6^{\circ}$ ano do ensino fundamental, no que se refere à consciência textual com foco na coerência, considerando a leitura de fábula.

Quanto à investigação sobre elaboração e validação de instrumento de consciência linguística, Raymundo (2006) elaborou instrumentos de avaliação do nível de consciência linguística de aprendizes adultos de inglês, falantes nativos de português, bem como submeteu tais instrumentos ao processo de validação. Para realizar o processo completo de validação, foram elaborados dez instrumentos, que passaram por três tipos de validação: conteúdo, critério e construto. Souza e Heinig (2015), também investigando a consciência linguística, apresentaram instrumentos e procedimentos de pesquisa na investigação de processos e produtos de leitura e escrita.

Quanto aos pressupostos teóricos que embasaram a elaboração do instrumento aqui apresentado, discorre-se, inicialmente, sobre a definição de leitura aqui adotada. Pela concepção psicolinguística, que ampara esse estudo, a leitura é definida como atividade cognitiva de construção de sentidos que resulta na compreensão. Desse modo, trata-se de um processo complexo realizado a partir da relação entre os elementos linguísticos e textuais e os conhecimentos que o leitor traz armazenado na memória (KOCH; ELIAS, 2011).

Assim, algumas variáveis intervenientes influenciam no processo de compreensão. O próprio texto é uma dessas variáveis, visto que o gênero textual e suas especificidades linguísticas (léxico, estrutura sintática, aspectos visuais, etc.) auxiliam ou dificultam o processo (COLOMER; CAMPS, 2002). O conhecimento prévio também constitui variável essencial, pois o leitor utiliza seus esquemas conceituais e linguísticos armazenados na memória para construir o sentido do texto, relacionando as informações obtidas no texto com aquelas que já possui, sejam elas linguísticas, textuais ou relacionadas a conhecimentos gerais de mundo (SMITH, 2003; KLEIMAN, 2013).

Sousa e Hübner (2015) apontam o próprio leitor como outra variável, o que abrange elementos relacionados às diferenças individuais, incluindo motivação, conhecimento do conteúdo do texto, memória de trabalho, atenção, entre outros diversos aspectos concernentes à complexidade humana. Os objetivos de leitura, segundo Solé (1998), também determinam como se dará a compreensão, pois direcionam a atenção do leitor para os elementos relevantes para compreender determinado texto, influenciam no acionamento dos esquemas necessários para auxiliar na construção do sentido e guiam o leitor na escolha dos procedimentos e estratégias que deve realizar e utilizar ao longo da leitura.

Desse modo, considera-se, neste estudo, que a compreensão leitora engloba três instâncias: o leitor, o texto e a interação que se dá entre eles (SPINILLO, 2013). A complexidade existente nessas relações não permite que os textos tenham sentido único, visto que, na construção de sentidos que envolve a compreensão, muitos são os fatores que podem levar a visões diferentes de um mesmo texto, como os vários citados anteriormente. No entanto, nem toda e qualquer interpretação é possivel, pois é necessário que o leitor realize inferências e levante hipóteses que estejam amparadas na materialidade linguística do texto, ou seja, que sejam autorizadas pelo texto.

Para que consiga chegar à compreensão por meio da realização dessas inferências e do levantamento de hipóteses, o leitor faz uso de estratégias de leitura. Estas referem-se a atividades mentais realizadas ao longo da interação com o texto para construir o sentido (SOLÉ, 1998; KLEIMAN, 2013). Goodman (1991) as define como 
esquemas para obter, avaliar e utilizar as informações. Assim, ajudam o leitor a selecionar, avaliar, persistir e alterar/abandonar as hipóteses que cria ao longo da leitura (SOLÉ, 1998).

Autores que estudam o assunto classificam as estratégias em cognitivas e metacognitivas (LEFFA, 1996; SOLÉ, 1998; KATO, 2007; KLEIMAN, 2013). As cognitivas são utilizadas de forma inconsciente, sem que o leitor tenha percepção sobre elas, enquanto as metacognitivas estão relacionadas às atividades realizadas intencionalmente, atribuindo caráter reflexivo ao processo de compreensão.

Neste estudo, o instrumento de pesquisa foi elaborado para investigar o uso da estratégia de predição. Essa estratégia de leitura envolve a antecipação de conteúdos do texto por meio da relação entre os conhecimentos prévios do leitor e as pistas linguísticas presente no texto (GOODMAN, 1976; 1991; SMITH, 2003). Salienta-se que tais antecipações não são realizadas por meio de adivinhações inconsequentes, com apostas realizadas sem base alguma.

Spinillo e Mahon (2015) definem uma predição como apropriada quando é plausivel de acordo com o que é veiculado no texto, mesmo que a hipótese não se confirme. Por outro lado, definem como inapropriada quando a hipótese levantada não tem relações com as informações do texto. Nesse sentido, a leitura eficiente envolve a habilidade do leitor de considerar os elementos importantes do texto na produção de predições apropriadas. Segundo Goodman (1976), tais hipóteses são confirmadas, rejeitadas ou reelaboradas durante o processo de compreensão.

A consciência linguistica ou a metalinguagem, como já citadas, envolve a capacidade de um individuo de refletir sobre o funcionamento da língua de modo consciente. Segundo Maluf e Gombert (2008), a consciência é desenvolvida a partir do tratamento da língua como objeto de análise e reflexão, por meio do qual o leitor planeja e monitora os seus processos linguísticos.

Desse modo, a consciência linguística está relacionada a diferentes habilidades, considerando os elementos linguísticos focalizados (fonema, morfema, estrutura sintática, sentido etc.) em cada situação de análise e reflexão (BARRERA,
2003). Gombert (1992), em seus estudos sobre metalinguagem, foi o primeiro autor a utilizar a expressão consciência textual, definindo-a como capacidade do leitor de voltar sua atenção para os elementos textuais, tornando o texto objeto de análise. Esse é o tipo de consciência abordada no protocolo verbal do instrumento de pesquisa apresentado neste estudo.

De acordo com Gombert (1992), o monitoramento que envolve o desenvolvimento da consciência textual considera os aspectos formais do texto e as informações nele apresentadas, ou seja, a forma e o conteúdo. Assim, o desenvolvimento dessa consciência envolve aspectos como a estrutura do texto - elementos formais que categorizam o texto como pertencente a um gênero textual; a coerência, que envolve as relações de conteúdo internas e externas do texto; a coesão, estabelecida pelos elementos conectivos que ligam as partes do texto, contribuindo para o estabelecimento do sentido; e a consciência procedimental, estabelecida pela reflexão do leitor acerca dos procedimentos que utiliza para compreender o texto.

No que se refere à estrutura do texto - chamada de superestrutura por Gombert (1992) -, os elementos focalizados estão relacionados ao formato do texto. Pereira (2013) declara que a superestrutura envolve os traços que estabelecem a identificação do texto como de determinado gênero textual, com o auxilio da situação comunicativa - envolvendo autor, leitor, tempo, espaço e suporte - e do modo de organização textual (moldura, componentes constitutivos, sequências dominantes e traços linguísticos-estruturais).

Quanto à coesão, Halliday e Hasan (1976) declaram que está relacionada à microestrutura do texto e suas relações de significado, contribuindo para a amarração do texto. Desse modo, contribuem para a integração entre os elementos do texto. A coesão é subdividida em coesão gramatical e coesão lexical, dependendo do recurso coesivo utilizado (HALLIDAY; HASAN, 1976).

A coesão lexical envolve o estabelecimento de sentido a partir de itens lexicais. Esse tipo de coesão pode ser estabelecido por: reiteração substituição da mesma palavra ou expressão a fim 
de evitar repetições -, por meio sinonímia (substituição de palavras ou expressões por sinônimos) e superordenado (nomes gerais que englobam uma determinada classe de palavras, incluindo os hipônimos e hiperônimos em relação de inclusão); e colocação (contiguidade) - associação de itens lexicais por meio dos campos semânticos.

Já a coesão gramatical refere-se às relações linguísticas de retomada estabelecidas por meio de itens gramaticais. Ocorre por meio de referência - uso de pronomes, artigos, advérbios e demais itens gramaticais; elipse - supressão de vocábulos ou expressões que podem ser subentendidos pelo contexto do texto; e conjunção - uso de elementos conectivos formais que auxiliam no estabelecimento do sentido do texto.

No que diz respeito à coerência textual, considera-se as relações de sentido internas e externas do texto, tanto no nível microestrutural como no nivel macroestrutural (CHAROLLES, 1998). O autor indica quatro metarregras como elementos que estabelecem essas relações: metarregra de manutenção temática - um texto, para ser coerente, necessita apresentar ideias que girem em torno de um mesmo eixo temático do início ao fim; metarregra de progressão temática - embora o assunto do texto deva ser mantido em sua totalidade, deve progredir e se desenvolver, de modo a não repetir as mesmas informações; a metarregra de não contradição interna - o texto não pode apresentar afirmações ou ideias opostas, para não tornar-se contraditório; e metarregra de relação com o mundo - os fatos, as ações, os eventos e os estados apresentados no texto devem ter relação de verdade com o mundo.

Pereira e Scliar-Cabral (2012) afirmam que há, ainda, outros fenômenos metacognitivos que constituem a consciência textual. São eles, por exemplo: a capacidade de monitoramento da leitura, envolvendo os comportamentos metalinguísticos, quando o leitor julga e explicita verbalmente os critérios utilizados na leitura ou para responder a alguma questão de compreensão leitora; a escrita; a revisão e a manipulação de partes do texto.

Considerando os fundamentos teóricos apresentados, define-se que o instrumento elaborado foi construido com base na concepção de que a predição leitora possui relação estreita com a consciência textual (BARETTA; PEREIRA, 2019), visto que, para elaborar suas hipóteses, é necessário que o leitor monitore o texto. Desse modo, as predições apropriadas são realizadas quando o leitor relaciona as informações do texto aos seus conhecimentos prévios linguisticos, textuais e de mundo para evitar formular hipóteses incoerentes.

Apresentados os pressupostos teóricos acerca do processo de validação de instrumentos e da elaboração do instrumento do estudo, na seção a seguir é descrito o instrumento e seu processo de validação.

\section{Metodologia}

O objetivo do estudo foi verificar se há evidência de validade do conteúdo e da confiabilidade de uma tarefa de predição leitora. Tendo em vista esse objetivo, orientaram a pesquisa as seguintes questões: a) Há evidências de validade de conteúdo pela análise de juizes?; b) Há evidências de validade de conteúdo pela análise das respostas dos participantes?; e c) Há consistência interna dos itens?

\subsection{Participantes}

Participaram como juízes para a validação da tarefa três professoras universitárias, com doutorado na área de Psicolinguística e cinco professores de Língua Portuguesa com experiência docente na disciplina. Esses profissionais foram selecionados para analisar o instrumento quanto à pertinência conceitual (abrangência do conteúdo), à clareza, à adequação da linguagem, e à forma de apresentação.

Responderam à tarefa 16 alunos com idade entre 11 e 13 anos, de classe média, frequentando o $6^{\circ}$ ano do ensino fundamental de uma escola pública federal da cidade de Porto Alegre/RS. Destes, seis eram do sexo feminino e 10 , do sexo masculino.

\subsection{Instrumentos}

\subsubsection{Tarefa de uso da predição leitora}

A tarefa analisada tem como objetivo obter dados sobre o desempenho no uso da estratégia de predição leitora. O instrumento foi elaborado com base na leitura da fábula A raposa e o corvo. 
Tendo em vista o objetivo de investigar a realização de predições, o instrumento foi elaborado em formato segmentado. Desse modo, o texto foi dividido em sete partes. Nessa segmentação de cada parte, foi considerada a possibilidade de que predições pudessem ser realizadas a respeito do conteúdo que estava por vir texto. Em função disso, os trechos de cada ficha apresentaram tamanhos variados. Cada trecho era seguido de uma pergunta que estimulava o uso da predição. Além disso, a fim de compreender o processo cognitivo realizado durante as predições, para cada pergunta de predição havia uma questão correspondente sobre os aspectos considerados pelo leitor para chegar a cada resposta (consciência textual).

As partes em que o texto foi dividido, bem como as perguntas de predição são apresentadas no Quadro 1.

Quadro 1 - Partes do texto e perguntas de predição

\section{Trecho 1}

\section{A raposa e o corvo}

Os corvos sempre tiveram fama de serem péssimos cantores. Ninguém gosta de ouvi-los. Apesar disso, um deles sempre foi muito vaidoso e não entendia por que era menosprezado pelos outros animais.

Certo dia, uma raposa faminta estava passando embaixo de uma árvore, quando viu lá em cima o corvo empoleirado num galho. Tinha no bico um grande pedaço de queijo.

1. O que a raposa vai fazer depois de avistar o corvo?

\section{Trecho 2}

A raposa parou e disse:

- Amigo corvo, sabe que não existe nenhuma outra ave que cante melhor que você? Elas não sentem inveja sempre que você canta?

2. O que vai acontecer a seguir?

\section{Trecho 3}

O corvo, acreditando no que ouvira, ficou feliz com o elogio. Finalmente alguém reconhecia seu talento de cantor.

A raposa então the pediu:

3. O que a raposa pedirá ao corvo?

\section{Trecho 4}

- Será que você poderia deliciar-me com uma de suas melodias?

4. O que vai acontecer a seguir?

\section{Trecho 5}

Orgulhoso e de peito estufado, o corvo se pôs a cantar para mostrar sua voz.

5. O que vai acontecer depois que o corvo começar a cantar?

\section{Trecho 6}

Mas, ao abrir o bico, derrubou o queijo perto da raposa que o pegou e, antes de sair correndo para saboreá-lo, disse: 6. O que a raposa vai dizer ao corvo?

\section{Trecho 7}

—Caro corvo, sua vaidade é maior que sua inteligência!

7. Considerando que as fábulas transmitem um ensinamento, qual será o ensinamento transmitido pela fábula A raposa e o corvo?

Moral: A vaidade é amiga dos tolos.

Fonte: As autoras (2020). 


\subsubsection{Questionário de avaliação da tarefa de predição leitora \\ O questionário enviado aos juizes divide-se em} duas partes. A primeira parte tem como objetivo analisar o instrumento como um todo, considerando aspectos como adequação conceitual, clareza e correção. Para tanto, os juizes deveriam indicar, em uma escala com três opções (sim - em parte - não), seu nivel de concordância com o critério apresentado.

A segunda parte, por sua vez, tinha o objetivo de avaliar cada item isoladamente. Nesse sentido, os respondentes deveriam assinalar, em uma escala Likert, a opção que apresenta sua opinião acerca da relevância de cada item do instrumento com relação às ideias principais da narrativa, de acordo com os seguintes critérios: 1 . não relevante; 2 . pouco relevante; 3. relevante e 4. muito relevante.

As perguntas que compõem o questionário são apresentadas no Quadro 2 a seguir:

Quadro 2 - Questionário de avaliação da tarefa de predição leitora

\section{Parte 1: Adequação do instrumento}

1. Os itens que compõem o instrumento têm o objetivo de avaliar o uso da estratégia de predição leitora durante a leitura de uma fábula. Você considera que este objetivo poderá ser alcançado?

a) Que problemas você encontrou? (opcional)

b) Que sugestões você tem a fazer? (opcional)

2. As perguntas de justificativa que compõem o instrumento têm o objetivo de avaliar a consciência textual com relação ao uso da estratégia de predição leitora durante a leitura de uma fábula. Você considera que este objetivo poderá ser alcançado?

a) Que problemas você encontrou? (opcional)

b) Que sugestões você tem a fazer? (opcional)

3. As instruções fornecidas são objetivas, precisas e completas?

a) Que problemas você encontrou? (opcional)

b) Que sugestões você tem a fazer? (opcional)

4. A apresentação do instrumento é adequada?

a) Que problemas você encontrou? (opcional)

b) Que sugestões você tem a fazer? (opcional)

5. As alternativas são adequadas ao conteúdo dos itens e evitam o processo de eliminação de respostas?

a) Que problemas você encontrou? (opcional)

b) Que sugestões você tem a fazer? (opcional)

6. A linguagem está correta e adequada ao público?

a) Que problemas você encontrou? (opcional)

b) Que sugestões você tem a fazer? (opcional)

7. O grau de dificuldade está adequado ao público? 


\section{Parte 2: Relevância dos itens}

\begin{tabular}{|c|c|c|c|c|c|}
\hline IItem & $\begin{array}{l}1 \\
\text { Não relevante }\end{array}$ & $\begin{array}{c}2 \\
\text { Pouco relevante }\end{array}$ & $\begin{array}{c}3 \\
\text { Relevante }\end{array}$ & $\begin{array}{c}4 \\
\text { Muito relevante }\end{array}$ & Observações \\
\hline & & & & & \\
\hline & & & & & \\
\hline & & & & & \\
\hline & & & & & \\
\hline & & & & & \\
\hline & & & & & \\
\hline & & & & & \\
\hline & & & & & \\
\hline
\end{tabular}

Fonte: As autoras (2020).

\subsection{Procedimentos}

Por se tratar de uma investigação que envolve seres humanos, a pesquisa da qual o estudo aqui apresentado faz parte foi submetida ao Comitê de Ética da PUCRS (CEP) e aprovada sob o protocolo de Certificado de Apresentação e Apreciação Ética (CAAE) n 55681216.6.0000.5336.

Para realizar o processo de validação, inicialmente realizou-se a validação de conteúdo. Para a composição do painel de juizes foram selecionados pesquisadores psicolinguistas de diferentes universidades da região sul do país e professores de Língua Portuguesa da instituição pesquisada.

Após a seleção dos participantes, os juizes foram convidados a participar da validação do instrumento por meio de correspondência enviada via e-mail. Nessa correspondência, foi encaminhado o instrumento de pesquisa, juntamente com o link de um formulário elaborado no programa JotForm $₫,{ }^{3}$ contendo o Questionário de avaliação da tarefa de uso da predição leitora e instruções de como proceder para respondê-lo. Foi dado um prazo de 20 dias a partir do envio da carta para que os especialistas pudessem avaliar o instrumento e emitir seus pareceres e sugestões. O tempo médio entre o envio e a devolução dos questionários foi de uma semana.

A tarefa de predição leitora, por sua vez, foi aplicada a todos os alunos conjuntamente, durante o turno regular de aulas, em dois periodos subse- quentes destinados à disciplina de Língua Portuguesa. Para a coleta dos dados, os participantes foram informados de que leriam uma fábula. No entanto, o texto seria apresentado por partes. Eles foram orientados a ler cada trecho com atenção e a responder às perguntas propostas, tentando imaginar o que aconteceria em seguida no desenrolar da narrativa. Foram orientados também a relatar, por escrito, se, para responder à pergunta, observaram alguma pista (palavra, expressão etc.) apresentada no texto ou se se basearam em seus conhecimentos anteriores. As fichas eram distribuidas à medida que cada participante completava e devolvia a anterior. Uma vez entregue, não era permitido consultá-la ou alterá-la (BARETTA; PEREIRA, 2019).

\subsection{Análise dos dados}

Primeiramente, foram analisadas as respostas dos juizes para verificar a adequação do instrumento quanto ao seu objetivo, sua clareza e sua correção. No questionário de avaliação da tarefa, os juizes, inicialmente, deveriam avaliar a tarefa como um todo, indicando se os aspectos apresentados estavam contemplados no instrumento. Para a análise desses dados, utilizou-se o método de porcentagem de concordância, calculada com base na seguinte fórmula (ALEXANDRE; COLUCI, 2011):

$\%$ de concordância Número de participantes que concordaram $\times 100$ Número total de participantes 
Considerou-se uma concordância de 90\% entre os juizes como critério para considerar que o quesito foi alcançado.

Para a segunda parte do questionário, os juízes classificaram a qualidade dos itens da tarefa em uma escala Likert que vai de 1 a 4 pontos. Com base nos dados obtidos, calculou-se o Índice de Validade de Conteúdo (IVC). O IVC mede a porcentagem de concordância entre os juízes sobre determinados quesitos dos itens de um instrumento (ALEXANDRE; COLUCI, 2011).

Para calcular o escore do IVC de cada item, foram considerados somente os itens marcados com os valores 4 e 5 da escala Likert. Sendo assim, a fórmula para calcular o IVC dos itens é (ALEXANDRE; COLUCI, 2011):

$$
\text { IVC }=\frac{\text { Número de respostas } 4 \text { ou } 5}{\text { Número total de respostas }}
$$

Para avaliar o instrumento como um todo, utilizou-se o valor de IVC de cada item. Uma concordância de, pelo menos $80 \%$ entre os juizes serviu de critério de decisão para determinar a relevância dos itens.

Para avaliar a tarefa de uso da predição leitora, as respostas dos alunos foram quantificadas com base nos seguintes critérios (SPINILLO; ALMEIDA, 2014, p. 123-124):

a) Categoria 1 (improvável): o participante apresenta respostas incoerentes, improváveis de ocorrer tendo em vista o que foi veiculado no texto até então. Nessa categoria foram também agrupadas respostas que não resultam de um processo de predição, constituindo uma mera repetição de partes do texto sem responder à pergunta.

b) Categoria 2 (plausivel, mas incompleta): o participante apresenta respostas coerentes, geradas a partir de informações do texto e de conhecimentos prévios do leitor. Apesar de apropriadas, as respostas classificadas nesta categoria são consideradas incompletas, pois informações importantes são omitidas.

c) Categoria 3 (plausivel e completa): respostas classificadas nesta categoria se assemelham àquelas da catego- ria II, porém consistem em respostas completas, sem que haja omissões de aspectos relevantes que atendam ao que é solicitado na pergunta.

Na correção dessas perguntas, foram atribuídos 2 (dois) pontos para as respostas classificadas na categoria 3, 1 (um) ponto para as classificadas na categoria 2 e o (zero) para a categoria 1. Cada participante poderia alcançar o máximo de $14 \mathrm{e}$ o mínimo de o (zero) pontos.

Para avaliar as perguntas de justificativa (consciência textual), as respostas dos participantes foram analisadas de acordo com os seguintes niveis (GOMBERT, 1992; POERSCH, 1998; SPINILLO, 2009; BARETTA; PEREIRA, 2019):

a) Nivel 1 (estado subconsciente): nivel de consciência mais elementar, caracterizado pela pouca capacidade de explicitação das informações utilizadas para realizar as predições. O participante encontra-se nesse nivel de consciência quando responde à questão de forma confusa e equivocada.

b) Nivel 2 (comportamento epilinguistico): nivel de consciência intermediário, caracterizado pela capacidade relativa de explicitação das informações utilizadas para realizar as predições. 0 participante encontra-se nesse nivel de consciência quando oferece indícios de como processou a questão, mas com formulações vagas e imprecisas.

c) Nivel 3 (comportamento metalinguistico): nivel de consciência mais avançado, caracterizado pela capacidade de explicitação das informações utilizadas para realizar as predições. O participante encontra-se nesse nivel de consciência quando demonstra ser capaz de fazer reflexões sobre o texto e sobre seus procedimentos de análise de forma clara e articulada.

Na correção dessas respostas, foram atribuidos 2 (dois) pontos para as classificadas no nivel 3, 1 (um) ponto para as classificadas no nivel 2 e o (zero) para o nivel 1. Cada participante poderia alcançar o máximo de 14 e o minimo de o (zero) pontos. 


\section{Resultados}

De acordo com os objetivos propostos, primeiramente foi verificada a análise realizada pelo painel de juizes. As respostas dos participantes com relação à adequação do instrumento são apresentadas na Tabela 1, onde (1) indica que o participante assinalou "sim" e (0) indica que a resposta apresentada foi "não" ou "em parte".

Tabela 1 - Resultados da validação de conteúdo - Adequação do instrumento

\begin{tabular}{cccccccccc}
\hline Critérios & A1 & A2 & A3 & A4 & A5 & A6 & A7 & A8 & \% por quesito \\
\hline Avaliação da Predição leitora & 1 & 1 & 1 & 1 & 1 & 1 & 1 & 1 & $100 \%$ \\
Avaliação da Consciência textual & 1 & 1 & 0 & 0 & 1 & 1 & 1 & 1 & $75 \%$ \\
Instruções objetivas & 1 & 1 & 1 & 1 & 1 & 1 & 1 & 1 & $100 \%$ \\
Apresentação adequada & 1 & 1 & 1 & 1 & 1 & 1 & 1 & 1 & $100 \%$ \\
Adequação das alternativas & 1 & 1 & 0 & 1 & 0 & 0 & 1 & 0 & $50 \%$ \\
Adequação da linguagem & 1 & 1 & 1 & 1 & 1 & 1 & 1 & 1 & $100 \%$ \\
Grau de dificuldade & 1 & 1 & 1 & 1 & 1 & 1 & 1 & 1 & $100 \%$ \\
\hline
\end{tabular}

Fonte: As autoras (2020).

Considerando o critério de concordância de 90\% entre juizes, apenas dois quesitos não alcançaram essa porcentagem: a capacidade do instrumento para avaliar a consciência textual e a adequação das alternativas. Com relação ao primeiro tópico, os juizes que não concordaram comentaram que a instrução "Como você pensou para responder?", apresentada nas perguntas de justificativa que avaliavam a consciência textual dos estudantes, levava o leitor a refletir sobre o percurso de seu pensamento, caracterizando-se como um conhecimento metacognitivo, e não sobre os elementos intratextuais e extratextuais considerados pelo leitor para chegar à resposta. Tendo em vista esse aspecto, um dos juizes sugeriu que o enunciado dessas perguntas poderia orientar o leitor a analisar as marcas linguisticas e/ou textuais presentes na fábula, para caracterizar a consciência textual. Sendo assim, para o enunciado das perguntas de justificativa foi alterado, conforme apresentado no Quadro 3.

Quadro 3 - Modificações no enunciado das perguntas de justificativa

\begin{tabular}{|c|c|}
\hline Versão original & Versão modificada \\
\hline Como você pensou para responder? & $\begin{array}{c}\text { O que o levou a pensar isso? Para responder à pergunta, você obser- } \\
\text { Explique. } \\
\text { seou em seus conhecimentos anteriores, coisas que você já conhecia } \\
\text { antes mesmo de ler o texto? Explique com suas palavras. }\end{array}$ \\
\hline
\end{tabular}

Fonte: As autoras (2020).

O segundo quesito em que não houve concordância entre os juizes foi a adequação das alternativas que acompanhavam os itens. Um dos avaliadores considerou que o formato de perguntas objetivas de escolha simples não permitiria analisar a capacidade de realizar predições e sim de selecionar hipóteses elaboradas pela pesqui- sadora. Outro avaliador comentou a possibilidade de que os participantes escolhessem uma alternativa ao acaso, o que prejudicaria a validade dos dados. Alguns avaliadores também observaram que, em determinados itens, havia mais de uma alternativa de resposta plausivel de acordo com as informações apresentadas no texto. 
Tendo em vista essas considerações, optou-se pela exclusão das alternativas e pela apresentação de perguntas de resposta aberta. Com isso, as respostas dos estudantes deixaram de ser classificadas em acerto ou erro e passaram a ser classificadas em categorias de acordo com sua plausibilidade, conforme explicitado na seção "análise dos dados".

A segunda etapa da validação de conteúdo é a análise da relevância dos itens. A Tabela 2 apresenta as respostas dos avaliadores.

Tabela 2 - Resultados da validação de conteúdo - Relevância dos itens do instrumento

\begin{tabular}{|c|c|c|c|c|c|c|c|c|c|c|}
\hline Itens & $\mathrm{A}_{1}$ & A2 & A3 & A4 & A5 & A6 & A7 & A8 & IVC & $\%$ \\
\hline 1 & 4 & 4 & 4 & 4 & 4 & 4 & 4 & 4 & 1 & 100 \\
\hline 2 & 2 & 3 & 4 & 4 & 2 & 4 & 4 & 2 & 0,62 & 62 \\
\hline 3 & 4 & 4 & 4 & 4 & 4 & 4 & 4 & 4 & 1 & 100 \\
\hline 4 & 3 & 3 & 4 & 4 & 3 & 4 & 4 & 2 & 0,87 & 87 \\
\hline 5 & 4 & 4 & 4 & 4 & 4 & 4 & 4 & 4 & 1 & 100 \\
\hline 6 & 4 & 4 & 3 & 3 & 3 & 4 & 4 & 4 & 1 & 100 \\
\hline 7 & 4 & 4 & 4 & 4 & 4 & 4 & 4 & 4 & 1 & 100 \\
\hline
\end{tabular}

Fonte: As autoras (2020).

Com relação à relevância dos itens, apenas o item 2 não alcançou a porcentagem de $80 \%$ de concordância entre os juízes. Na versão original do instrumento, o item 2 perguntava, após o trecho "- Amigo corvo, sabe que não existe nenhuma outra ave que cante melhor que você? Elas não sentem inveja sempre que você canta?", se o corvo acreditaria no elogio da raposa. Os juizes consideraram que essa pergunta não seria relevante, uma vez que exigiria apenas a escolha entre duas possibilidades: acreditar ou não acreditar. Um dos avaliadores sugeriu que o item seria mais relevante se a pergunta fosse mais ampla, permitindo que o aluno apresentasse uma gama maior de informações. Sendo assim, na versão final do instrumento o referido item foi reformulado conforme mostrado no Quadro 4.

Quadro 4 - Modificações no item 2

\begin{tabular}{|c|c|}
\hline Versão original & Versão modificada \\
\hline $\begin{array}{c}\text { O corvo acreditará no } \\
\text { elogio da raposa? }\end{array}$ & $\begin{array}{c}\text { O que vai acontecer a } \\
\text { seguir? }\end{array}$ \\
\hline
\end{tabular}

Fonte: As autoras (2020).
Depois de efetuadas as modificações, procedeu-se à aplicação-piloto da tarefa, realizada com 16 estudantes do $6^{\circ}$ ano de uma escola pública federal.

Com base nos resultados obtidos, realizou-se a análise da consistência interna do instrumento. Para tanto, utilizou-se o coeficiente alfa de Cronbach, método estatístico empregado para avaliar a confiabilidade dos itens de um teste. O valor de alfa varia entre o e 1. Entende-se, então, que quanto mais perto de 1 estiver o valor da estatística, maior é a consistência do questionário. O valor mínimo aceitável para se considerar um questionário confiável é $\alpha=0,6$ (LANDIS; KOCH, 1977).

Foi obtido um coeficiente alfa de Cronbach de 0,8099, considerado muito bom na área de psicometria (LANDIS; KOCH, 1977).

Procedeu-se também à análise acerca de quais itens contribuíram mais positiva ou negativamente para a consistência interna da tarefa. Desse modo, calculou-se o coeficiente alfa de Cronbach para o caso em que cada item fosse excluido. Os resultados encontrados são apresentados na Tabela 3. 
Tabela 3 - Coeficiente alfa de Cronbach em caso de exclusão de item (aplicação-piloto)

\begin{tabular}{cc}
\hline Item & $\begin{array}{c}\text { Alfa de Cronbach } \\
\text { para exclusão de item }\end{array}$ \\
\hline $\mathbf{1}$ & 0,8174 \\
$\mathbf{2}$ & 0,7404 \\
$\mathbf{3}$ & 0,8217 \\
$\mathbf{4}$ & 0,7493 \\
$\mathbf{5}$ & 0,7567 \\
$\mathbf{6}$ & 0,7746 \\
$\mathbf{7}$ & 0,8147 \\
\hline
\end{tabular}

Fonte: As autoras (2020).

A partir dos dados da tabela, observa-se que o item 2 é o que contribui mais negativamente, enquanto o item 3 é o que contribui mais positivamente para a consistência interna. O intervalo de variação de quase 1 ponto pode ser atribuido, nesse caso, ao número reduzido de itens da tarefa, uma vez que quanto menos itens tiver um instrumento, maior será a influência de cada um no teste. Essa influência, no entanto, não chega a ser relevante, pois, mesmo com a exclusão de algum item, o coeficiente fica no intervalo [0,7404; 0,8217], considerado adequado para os padrões psicométricos.

Buscou-se também evidência de validade de conteúdo com base na estrutura do instrumento. Analisaram-se as respostas dos estudantes para verificar se os itens eram suficientes e apropriados para avaliar o uso da predição leitora, tendo como base as três categorias e niveis de respostas apresentadas na seção 2. Esses dados aparecem na Tabela 4.

Tabela 4 - Número e porcentagem de respostas às perguntas de uso da predição leitora e de justificativa, considerando as categorias e os niveis de respostas

\begin{tabular}{ccccccc}
\hline Item & $\mathbf{C 1}$ & $\mathbf{C} 2$ & $\mathbf{C} 3$ & $\mathbf{N 1}$ & $\mathbf{N}$ & $\mathbf{N} 3$ \\
\hline $\mathbf{1}$ & $2(12,5 \%)$ & $7(43,7 \%)$ & $7(43,7 \%)$ & $3(18,7 \%)$ & $8(50,0 \%)$ & $5(31,2 \%)$ \\
$\mathbf{2}$ & $3(18,7 \%)$ & $4(25,0 \%)$ & $9(56,2 \%)$ & $3(18,7 \%)$ & $7(43,7 \%)$ & $6(37,5 \%)$ \\
$\mathbf{3}$ & $2(12,5 \%)$ & $5(31,2 \%)$ & $9(56,2 \%)$ & $2(12,5 \%)$ & $10(62,5 \%)$ & $4(25,0 \%)$ \\
$\mathbf{4}$ & $1(6,25 \%)$ & $3(18,7 \%)$ & $12(75,0 \%)$ & $2(12,5 \%)$ & $9(56,2 \%)$ & $5(31,2 \%)$ \\
$\mathbf{5}$ & $2(12,5 \%)$ & $6(37,5 \%)$ & $8(50,0 \%)$ & $4(25,0 \%)$ & $7(43,7 \%)$ & $5(31,2 \%)$ \\
$\mathbf{6}$ & $3(18,7 \%)$ & $3(18,7 \%)$ & $10(62,5 \%)$ & $6(37,5 \%)$ & $5(31,2 \%)$ & $5(31,2 \%)$ \\
$\mathbf{7}$ & $4(25,0 \%)$ & $5(31,2 \%)$ & $7(43,7 \%)$ & $4(25,0 \%)$ & $5(31,2 \%)$ & $7(43,7 \%)$ \\
Total & $17(15,1 \%)$ & $33(29,4 \%)$ & $62(55,3 \%)$ & $24(21,4 \%)$ & $51(45,5 \%)$ & $37(33,0 \%)$ \\
\hline
\end{tabular}

Nota $C_{1}$ = predição improvável; $C_{2}$ = predição plausivel, mas incompleta; $C_{3}$ = predição plausivel e completa; N1 = estado pré-consciente; N2 = comportamento epilinguístico; N3 = comportamento metalinguístico.

Fonte: As autoras (2020).

Quanto à validade de conteúdo com base nas respostas dos estudantes, observa-se que, em todos os itens, houve respostas classificadas nas três categorias de análise. Embora mais da metade das respostas tenha sido considerada apropriada, $44,4 \%$ das respostas oferecidas pelos participantes apresentavam pouca relação com o que era veiculado no texto (categoria 1) ou, embora apropriadas, omitiam informações importantes (categoria 2). Com relação às perguntas de consciência textual, a maior parte das respostas (45.5\%) concentrou-se no nivel 2 , caracterizado por um comportamento epilinguístico, isto é, quando o aluno oferece indícios de como processou a questão, mas de forma vaga e imprecisa. Houve também um aumento na porcentagem de respostas classificadas no nível 1 (estado subconsciente) com relação às 
respostas classificadas na categoria 1 (predições improváveis). Enquanto estas somaram 15,1\% das respostas, aquelas representaram $21,4 \%$. Tais dados sugerem que os estudantes apresentam maior dificuldade para explicar como realizaram a predição do que para realizá-la.

Esses resultados indicam a necessidade de situações de ensino com foco no uso dessa estratégia para que os alunos possam elaborar mais predições plausiveis e completas, relacionando as informações do texto e as informações provenientes do conhecimento prévio. O mesmo ocorre com relação à consciência textual sobre o uso dessa estratégia, uma vez que instruções específicas com foco na verbalização do processo realizado durante a leitura e dos elementos considerados na realização da tarefa permitiriam que os alunos realizassem mais atividades metalinguísticas (nivel 3).

Nesse sentido, examinando as categorias e niveis de respostas dos participantes, considerou-se que não havia itens que não pudessem ser respondidos ou que apresentassem um número tão elevado de respostas adequadas a ponto de alcançar efeito teto. Sendo assim, os itens foram julgados adequados para examinar o uso da predição e o a consciência sobre o uso dessa estratégia.

\section{Considerações finais}

Este estudo descreveu aspectos do processo de validação do conteúdo e da confiabilidade de uma tarefa de uso da predição leitora, realizado por meio de um estudo piloto, uma importante fase do desenvolvimento de uma pesquisa.

A validação de conteúdo, realizada por meio de um painel de juizes, foi importante para garantir que a tarefa realmente examinava aquilo que se propunha e fazer ajustes necessários para uma maior clareza dos itens. Além disso, ao examinar as respostas dos estudantes, foi possivel observar se as categorias de análises estabelecidas eram adequadas e suficientes para a análise das variáveis envolvidas no estudo, bem como o grau de dificuldade dos itens. Esses resultados também permitiram averiguar a confiabilidade do instrumento, por meio da consistência interna de seus itens. A partir dessa validação, considera- -se possivel a aplicação do instrumento a uma amostra maior e mais representativa.

Ademais, a tarefa utilizada nesse estudo pode ser útil em contextos escolares para o diagnóstico das dificuldades dos estudantes e da forma como processam a leitura, oferecendo ao professor suporte para o trabalho pedagógico.

Por fim, o presente estudo, ao relatar um estudo piloto para a validação de um instrumento de pesquisa, buscou mostrar a importância da realização desses estudos em pesquisas na área da linguística.

\section{Referências}

ALBUQUERQUE, Eliana; SPINILLO, Alina Galvão. O conhecimento de crianças sobre diferentes tipos de textos. Psicologia: teoria e pesquisa, Brasília, v. 13, n. 3 . p. 329-338, set./dez. 1997.

ALEXANDRE, Neusa Maria Costa; COLUCl, Marina Zambon Orpinelli. Validade de conteúdo nos processos de construção e adaptação de instrumentos de medidas. Ciência \& Saúde Coletiva, Brasilia, v. 16, n. 7 . p. 3061-3068, jul. 2011. https://doi.org/10.1590/S1413$\underline{81232011000800006}$

AMERICAN EDUCATIONAL RESEARCH ASSOCIATION, AMERICAN PSYCHOLOGICAL ASSOCIATION \& NATIONAL COUNCIL ON MEASUREMENT IN EDUCATION. Standards for educational and psychological testing. Washington: American Psychological Association, 1999.

ANÇÃ, Maria Helena Serra. Revisitando a consciência linguística: apropriação do conceito por parte de futuros professores de Português. Calidoscópio, São Leopoldo, v. 13, n. 1, p. 83-91, jan./abr. 2015. http:// dx.doi.org/10.4013/cld.2015.131.08

BARETTA, Danielle. Compreensão leitora e consciência textual na predição leitora: um estudo com alunos do $6^{\circ}$ ano do ensino fundamental a partir da leitura de uma fábula. 2017. 89 p. Dissertação (Mestrado em Letras) Pontifícia Universidade Católica do Rio Grande do Sul, Porto Alegre, 2017.

BARETTA, Danielle; PEREIRA, Vera Wannmacher. Predição leitora e consciência textual: um estudo com alunos do ensino fundamental. Ilha do Desterro, Florianópolis, v. 72, n. 3, p. 139-173, set./dez. 2019. https:// doi.org/10.5007/2175-8026.2019v72n3p139

BARRERA, Sylvia Domingos. Papel facilitador das habilidades metalinguisticas na aprendizagem da linguagem escrita. In: MALUF, Maria Regina (org.). Metalinguagem e aquisição da escrita: contribuições de pesquisa para a prática da alfabetização. São Paulo: Casa do Psicólogo, 2003. p. 65-90.

CASTRO, Joselaine Sebem de; PEREIRA, Vera Wannmacher. Leitor e texto: a preditibilidade faz a interação. Calidoscópio, São Leopoldo, v. 2, n. 1, p. 55-60, 2004. 
CHAROLLES, Michel. Introdução aos problemas de coerência dos textos: abordagem teórica e estudo das práticas pedagógicas. In: GALVES, Charlote; ORLANDI, Eni Puccinelli; OTONI, Paulo. (org.) O texto: leitura e escrita. Campinas: Pontes, 1998, p. 39-85.

COHEN, Andrew. Recent uses of mentalistic data in reading strategy research. D.E.L.T.A., São Paulo, v. 3, n. 1, p. $57-84,1987$

COLOMER, Teresa; CAMPS, Anna. Ensinar a ler, ensinar a compreender. Porto Alegre: Artmed, 2002.

CUNHA, Neide de Brito; SANTOS, Acácia Aparecida Angeli dos. Estudo de validade do questionário de avaliação de consciência metatextual. Psicologia: Teoria e Prática, São Paulo, v. 16, n. 1, p. 141-154, abr. 2014. http://dx.doi.org/10.15348/1980-6906/psicologia. v16n1p141-154

ERICSSON, Anders; SIMON, Herbert. Protocol analysis: verbal reports as data. Cambridge: MIT Press, 1993

EXNER, Charlotte. Content validity of the in-hand manipulation test. The American Journal of Occupational Therapy, Bethesda, v. 47, n. 6, p. 505-513, 1993. https:// doi.org/10.5014/ajot.47.6.505

FERREIRA, A. L:; SPINILLO, Alina Galvão. Desenvolvendo a habilidade de produção de textos em crianças a partir da consciência metatextual. In: MALUF, Maria Regina (org.). Metalinguagem e aquisição da escrita: contribuições da pesquisa para a prática da alfabetização. São Paulo: Casa do Psicólogo, 2003. p. 119-148.

GIASSON, Jocelyne. A compreensão na leitura. Tradução de Maria José Frias. Porto: ASA Editores, 2000.

GOMBERT, Jean-Émile. Metalinguistic development. Chicago: University of Chicago Press, 1992.

GOODMAN, Kenneth. Reading, a psycholinguist guessing game. In: SINGER, Harry; RUDDELL, Robert (org.) Theoretical models and processes of reading. Newark: International Reading Association, 1976. p. 497-508.

GOODMAN, Kenneth. Unidade na leitura: um modelo psicolinguístico transacional. Letras de Hoje. Porto Alegre, v. 26, n. 4, p. 9-43, 1991.

HALLIDAY, Michael; HASAN, Ruqaiya. Cohesion in English. London: Longman, 1976.

KATO, Mary Aizawa. O aprendizado da leitura. São Paulo: Martins Fontes, 2007.

KLEIMAN, Ângela. Texto e leitor: aspectos cognitivos da leitura. Campinas: Pontes, 2013.

$\mathrm{KOCH}$, Ingedore; ELIAS, Vanda Maria. Ler e compreender os sentidos do texto. São Paulo: Contexto, 2011.

LANDIS, Richard; KOCH, Gary. The measurement of observer agreement for categorical data. Biometrics, Washington, v. 33, n. 1, p. 159-174, 1977. https://doi. org/10.2307/2529310

LEFFA, Vilson. Aspectos da leitura: uma perspectiva psicolinguistica. Porto Alegre: Sagra-Luzzato, 1996.
LORANDI, Aline et al. Consciência linguistica: diferentes olhares. Letrônica, Porto Alegre, v. 5, n. 3, p. 21-44, jul./ dez. 2012.

MACIAS, Arturo Barraza. La consulta a expertos como estrategia para la recolección de evidencias de validez basadas en el contenido. Investigación Educativa Duranguense, n. 7. p. 5-14, 2007.

MALUF, Maria Regina; GOMBERT, Jean-Émile. Habilidades implícitas e controle cognitivo na aprendizagem da linguagem escrita. In: MALUF, Maria Regina; GUIMARÃES, Sandra Regina Kirchner (org.). Desenvolvimento da linguagem oral e escrita. Curitiba: Editora da UFPR, 2008. p. 123-135.

NEVES, Patricia de Andrade; BORGES, Caroline Bernardes. A consciência textual no gênero fábula: um instrumento de verificação da coerência com alunos do Ensino fundamental. Signo, Santa Cruz do Sul, v. 43, n. 77, p. 62-73, maio 2018. https://doi.org/10.17058/ signo.v43i77.11509.

NEVES, Patricia de Andrade; BORGES, Caroline Bernardes; BARETTA, Danielle. Considerações sobre a elaboração de um instrumento de verificação da consciência textual. Revista Ibero-Americana de Humanidades, Ciências e Educação, Criciúma, v. 6, n. 5, p. 34-46, maio 2020. https://doi.org/10.29327/211653.6.5-3.

PEREIRA, Vera Wannmacher. A predição na teia de estratégias de compreensão leitora. Confluência, Rio de Janeiro, v. 1, p. 81-91, 2012.

PEREIRA, Vera Wannamacher. Arrisque-se... faça seu jogo. Letras de Hoje, Porto Alegre, v. 37, n. 2, p. 47-63, 2002.

PEREIRA, Vera Wannmacher. Compreensão da leitura e consciência textual nos anos iniciais. Signo, Santa Cruz, v. 38, p. 29-43, mar. 2013. https://doi.org/10.17058/ signo.v38io. 4554

PEREIRA, Vera Wannmacher. Predição, compreensão e situação de compreensão. Desenredo, Passo Fundo, v. 7. n. 1, p. 91-103, 2011.

PEREIRA, Vera Wannmacher. Predição leitora: procedimentos e desempenhos em ambiente virtual e em ambiente não virtual. Letras de Hoje, Porto Alegre, v. 44, n. 3, p. 22-27, 2009

PEREIRA, Vera Wannmacher; SANTOS, Thais Vargas dos. Estratégia de leitura de predição na escola: uso e consciência linguística no seu uso. Linguagem em (Dis)curso, Tubarão, v. 17, n. 3, p. 361-380, set./dez. 2017. http://dx.doi.org/10.1590/1982-4017-170305-2117

PEREIRA, Vera Wannmacher; SCLIAR-CABRAL, Leonor. Compreensão de textos e consciência textual: caminhos para o ensino nos anos iniciais. Florianópolis: Insular, 2012.

POERSCH, José Marcelino. Uma questão terminológica: consciência, metalinguagem, metacognição. Letras de Hoje, Porto Alegre v. 33, n. 4, p. 7-12, 1998.

RAYMUNDO, Valéria Pinheiro. Elaboração e validação de um instrumento de avaliação de consciência linguistica 2006. 249 p. Tese (Doutorado em Linguística Aplicada) - Pontificia Universidade Católica do Rio Grande do Sul, Porto Alegre, 2006. 
RAYMUNDO, Valéria Pinheiro. Construção e validação de instrumentos: um desafio para a psicolinguística. Letras de Hoje, Porto Alegre, v. 44, n. 3, p. 86-93, jul./set. 2009

SHOHAMY, Elana. The role of language tests in the construction and validation of second-language acquisition theories. In: TARONE, Elaine; GASS, Susan; COHEN, Andrew (org.). Research Methodology in Second-Language Acquisition. New Jersey: Lawrence Erlbaum Associates publishers, 1994. p. 133-142.

SMITH, Frank. Compreendendo a leitura: uma análise psicolinguistica da leitura e do aprender a ler. Porto Alegre: Artes Médicas, 2003.

SOLÉ, Isabel. Estratégias de leitura. Porto Alegre: Artmed, 1998.

SOUSA, Lucilene Bender de; HÜBNER, Lilian Cristine. Desafios na avaliação da compreensão leitora: demanda cognitiva e leiturabilidade textual. Revista Neuropsicologia Latinoamericana, [S. I.], v. 7. n. 1, p. 34-46, 2015. http://dx.doi.org/10.5579/rnl.2013.0237

SOUZA, Ana Cláudia; HEINIG, Otilia Lizete de Oliveira Martins. Abordagens psicolinguísticas na pesquisa em leitura e escrita: instrumentos e procedimentos. Letras de Hoje, Porto Alegre, v. 50, n. 1, p. 22-31, 2015. https:// doi.org/10.15448/1984-7726.2015.1.18396

SPINILLO, Alina Galvão. A consciência metatextual. In: MOTA, Márcia da (org.). Desenvolvimento metalinguistico: questões contemporâneas. São Paulo: Casa do Psicólogo, 2009. p. 77-113.

SPINILLO, Alina Galvão. A dimensão social, linguística e cognitiva da compreensão de textos: considerações teóricas e aplicadas. In: MOTA, Márcia Peruzi da; SPINILLO, Alina Galvão (org.). Compreensão de textos. São Paulo: Casa do Psicólogo, 2013. p. 171-198.

SPINILLO, Alina Galvão; ALMEIDA, Denise Dias. Compreendendo textos narrativo e argumentativo: há diferenças? Arquivos Brasileiros de Psicologia, Rio de Janeiro, v. 66, n. 33, p. 115-132, 2014.

SPINILLO, Alina Galvão; MAHON, Érika da Rocha. "O que você acha que vai acontecer agora?" Um estudo sobre inferências de predição na compreensão de textos. In: NASCHOLD, Ângela; PEREIRA, Antônio; GUARESI, Ronei; PEREIRA, Vera Wannmacher (org.). Aprendizado da leitura e da escrita: a ciência em interfaces. Natal: EDUFRN, 2015. p. 163-188.

SPINILLO, Alina Galvão; MOTA, Márcia Maria Peruzzi Elia da; CORREA, Jane. Consciência metalinguística e compreensão de leitura: diferentes facetas de uma relação complexa. Educar em Revista, Curitiba, n. 38, p. 157-171, set./dez. 2010. http://dx.doi.org/10.1590/ S0104-40602010000300011

SPINILLO, Alina Galvão; PRATT, Chris. Sociocultural differences in children's genre knowledge. In: KOSTULI, Triantafillia (org.). Writing in context(s): textual practices and learning processes in sociocultural settings. New York: Springer, 2005. p. 27-48.
TOMITCH, Leda Maria Braga. Desvelando o processo de compreensão leitora: protocolos verbais na pesquisa em leitura. Revista Signo, Santa Cruz do Sul, v. 32. n. 53, p. 42-53, 2007. http://dx.doi.org/10.17058/ signo.v32i53.244

URBINA, Susana. Fundamentos da testagem psicológica. Porto Alegre: Artmed, 2007.

VIANNA, Heraldo Marelim. Testes em educação. São Paulo: IBRASA, 1978.

\section{Agradecimentos}

O presente trabalho foi realizado com apoio da Coordenação de Aperfeiçoamento de Pessoal de Nivel Superior - Brasil (CAPES) - Código de Financiamento 001.

\section{Danielle Baretta}

Doutoranda em Letras, com concentração em Linguística, na Pontifícia Universidade Católica do Rio Grande do Sul (PUCRS), em Porto Alegre, RS, Brasil. Bolsista parcial CAPES. Professora do Colégio Militar de Porto Alegre, RS, Brasil.

\section{Caroline Bernardes Borges}

Doutoranda em Letras, com concentração em Linguística, na Pontifícia Universidade Católica do Rio Grande do Sul (PUCRS), em Porto Alegre, RS, Brasil. Bolsista integral CAPES/PROEX.

\section{Patricia de Andrade Neves}

Doutoranda em Letras, com concentração em Linguística, na Pontificia Universidade Católica do Rio Grande do Sul (PUCRS), em Porto Alegre, RS, Brasil. Bolsista integral CNPq. Professora do Colégio Israelita de Porto Alegre, RS, Brasil.

\section{Endereço para correspondência}

Danielle Baretta

Pontificia Universidade Católica do Rio Grande do Sul Av. Ipiranga, 6.681, Prédio 9, sala 204

Partenon, 90619-900

Porto Alegre, RS, Brasil

Os textos deste artigo foram revisados pela Poá Comunicação e submetidos para validação do(s) autor(es) antes da publicação. 